\title{
The multiple functions of the endocannabinoid system: a focus on the regulation of food intake
}

\author{
Eduardo Tibiriça
}

\begin{abstract}
Background: Cannabis sativa (also known as marijuana) has been cultivated by man for more than 5,000 years. However, there was a rise in its use in the $20^{\text {th }}$ century for recreational, religious or spiritual, and medicinal purposes. The main psychoactive constituent of cannabis, whose structure was identified in the 1960's, is $\Delta^{9}$ tetrahydrocannabinol. On the other hand, the discovery of cannabinoid receptors and their endogenous agonists took place only very recently. In fact, the first cannabinoid receptor $\left(\mathrm{CB}_{1}\right)$ was cloned in 1990, followed 3 years later by the characterization of a second cannabinoid receptor $\left(\mathrm{CB}_{2}\right)$. Since the $19^{\text {th }}$ century, the use of cannabis has been reported to stimulate appetite and increase the consumption of sweet and tasty food, sometimes resulting in significant weight gain. The recent description of the endocannabinoid system, not only in the central nervous system but also in peripheral tissues, points to its involvement in the regulation of appetite, food intake and energy metabolism. Consequently, the pharmacological modulation of the over-activity of this system could be useful in the treatment of the metabolic syndrome.

Conclusions: The endocannabinoid system has important physiological functions not only in the central nervous system but also in peripheral tissues. The activation of central $\mathrm{CB}_{1}$ receptors, particularly in hypothalamic nuclei and in the limbic system, is involved in the regulation of feeding behavior, and especially in the control of the intake of palatable food. In the periphery, cannabinoid receptors are present in adipocytes, skeletal muscle, gastrointestinal tract and liver, modulating energy metabolism.
\end{abstract}

\section{Introduction}

\section{Historical aspects}

Cannabis sativa (marijuana or cannabis) has been cultivated by man since approximately 4,000 B.C $[1,2]$. At that time, the fibers obtained from the cannabis stems were mainly used to manufacture textiles and paper [1]. Moreover, from that time on, cannabis has also been known to have a variety of medicinal effects unrelated to its psychoactive properties, including effects on anorexia, emesis, pain, inflammation and neurodegenerative disorders [3]. Cannabis is the most widely used illicit drug in Western societies and also the one with the longest recorded history of human use. The popularity of marijuana as a recreational drug is due to its ability to alter sensory perception and cause elation and euphoria [2].

\footnotetext{
* Correspondence: etibi@ioc.fiocruz.br

* Correspondence: etibi@ioc.fiocruz.br
Laboratory of Cardiovascular Investigation, Oswaldo Cruz Institute, Fiocruz, Rio de Janeiro, Brazil
} Rio de Janeiro, Brazil

It has also been known since 300 B.C. that the recreational use of cannabis stimulates appetite, especially for sweet and palatable food $[4,5]$. Nevertheless, this phenomenon was seriously taken into consideration in biomedical research only in the last decade, after the description of the existence of an endogenous cannabinoid system [6,7], providing a physiological basis for the biological effects induced by cannabis and its derivatives. Several chemical constituents of cannabis have already been identified, but its main psychoactive constituent is considered to be $\Delta^{9}$-tetrahydrocannabinol $\left(\Delta^{9}\right.$-THC), whose structure was identified in the 1960's [8]. Even though several naturally-occurring agonists of the endogenous cannabinoid system have been known since then, the discovery of cannabinoid receptors and their endogenous agonists took place only very recently. In fact, the first cannabinoid receptor $\left(\mathrm{CB}_{1}\right)$ was cloned in 1990 [9], followed 3 years later by the characterization of a second cannabinoid receptor $\left(\mathrm{CB}_{2}\right)$ [10]. 


\section{The endocannabinoid system}

Cannabinoid receptors belong to the $G$ protein-coupled receptor superfamily and their activation modulates adenylate-cyclase, potassium and calcium channels and transcription factors such as mitogen-activated protein kinase $[6,11]$. The $\mathrm{CB}_{1}$ cannabinoid receptor is widely expressed in the central nervous system as well as in the periphery, while $C_{2}$ is mainly expressed in immune cells. In the central nervous system, $\mathrm{CB}_{1}$ is predominantly expressed presynaptically, modulating the release of neurotransmitters, including $\gamma$-aminobutyric acid (GABA), dopamine, noradrenaline, glutamate and serotonin [12].

The discovery of specific receptors mediating the actions of cannabis led to the search for endogenous ligands for cannabinoid receptors. The first endogenous cannabinoid, arachidonoyl ethanolamide, was identified in 1992 and was named anandamide, from the Sanskrit word 'ananda', meaning internal ecstasy $[13,14]$. Thus, both plant-derived $\left(\Delta^{9}\right.$-THC) and endogenous (anandamide) agonists bind to the same cannabinoid receptors (Figure 1). Since the discovery of anandamide, other polyunsaturated fatty acid derivatives acting as functional agonists of cannabinoid receptors have been characterized and collectively termed endocannabinoids [15]. In contrast to classical neurotransmitters such as the catecholamines, endocannabinoids are not stored in the interior of synaptic vesicles because of the high lipophilicity of these ligands [6]. These findings led to the conclusion that the endocannabinoid system acts "on demand", meaning that the endocannabinoids are synthesized and released upon physiological or pathological stimulation [6].

\section{The endocannabinoid system and the regulation of food intake and energy metabolism}

Since the $19^{\text {th }}$ century the use of cannabis has been reported to stimulate appetite and to increase the consumption of sweet and tasty food, sometimes resulting in significant weight gain $[4,16]$. The recent description of the endocannabinoid system, not only in the central nervous system but also in peripheral tissues, points to its involvement in the regulation of appetite, food intake and energy metabolism [17-20]. Numerous experimental data have confirmed this hypothesis and will be briefly summarized below, while clinical results will be presented in the next topic of this article.

\section{Endocannabinoid actions in the central nervous system}

It has already been demonstrated that endocannabinoids initiate appetite by stimulation of $\mathrm{CB}_{1}$ receptors in hypothalamic areas involved in the control of food intake, such as the ventromedial hypothalamus (VMH) [21] (Figure 2). For instance, the injection of anandamide in the VMH of pre-satiated rats induces hyperphagia, which is prevented by previous hypothalamic administration of the selective $\mathrm{CB}_{1}$ cannabinoid antagonist rimonabant [22]. Using another experimental approach, Kirkham et al. [23] evaluated endocannabinoid levels in relation to the feeding behavior of rats in the hypothalamus and in the limbic forebrain, including the shell area of the nucleus accumbens, which is known to be linked to eating motivation. Endocannabinoid levels increased during fasting and declined during feeding, while no changes were detected in satiated rats. On the other hand, endocannabinoid levels in the cerebellum, which is not directly involved in the control of food intake, were unaffected by feeding behavior. Moreover, the injection of endocannabinoids into the nucleus accumbens induced feeding behavior, an effect that was also attenuated by rimonabant [23].

The experimental model of $\mathrm{CB}_{1}$ receptor knockout $\left(\mathrm{CB}_{1^{-/-}}\right)$mice has also been used to clarify the involvement of the endocannabinoid system in the regulation of energy metabolism. An elegant study conducted by Ravinet-Trillou et al. compared $\mathrm{CB}_{1}-/$ - knockout male mice with wild-type animals $\left(\mathrm{CB}_{1+/+}\right)$ exposed either to a standard laboratory regimen or to a high-fat diet (HFD) [24]. When maintained on the standard diet, $\mathrm{CB}_{1^{-}} /$- mice are lean and their body weight and adiposity are, respectively, 24 and $60 \%$ lower than that of $\mathrm{CB}_{1}$ $+/+$ mice. $\mathrm{CB}_{1-/}-$ mice submitted to the HFD do not develop obesity and do not display hyperphagia in contrast to $\mathrm{CB}_{1+/+}$ mice, and their feeding efficiency remains low. Furthermore, the insulin resistance that occurs in HFD-fed mice is not present in $\mathrm{CB}_{1}-/$ - mice. These results led to the conclusion that $\mathrm{CB}_{1}$ receptors are involved not only in the development of dietinduced obesity but also in peripheral metabolic regulations [24]. These results were confirmed by Cota et al. [25], who showed that $\mathrm{CB}_{1-1-\text { mice exhibit reduced }}$ spontaneous caloric intake and total fat mass, decreased body weight, and hypophagia, when compared with $\mathrm{CB}_{1}$ $+/+$ littermates. Moreover, in young $\mathrm{CB}_{1-/}-$ mice, the lean phenotype is predominantly caused by decreased caloric intake, whereas in adult $\mathrm{CB}_{1}-/$ - mice, metabolic factors appear to contribute to the lean phenotype [25].

Another study carried out in mice submitted to HFD showed that a short-lasting reduction of food intake induced by a chronic oral treatment with rimonabant is dissociated from the long-lasting reduction of body weight and obesity. Moreover, rimonabant reverses the insulin resistance and lowered plasma leptin, insulin, and free fatty acid levels in this model of diet-induced obesity [26].

It is also noteworthy that $\Delta^{9}$-THC increases not only total food intake but also specifically increases the consumption of sweets, suggesting an interaction between the effect of the drug and the palatability of the food 


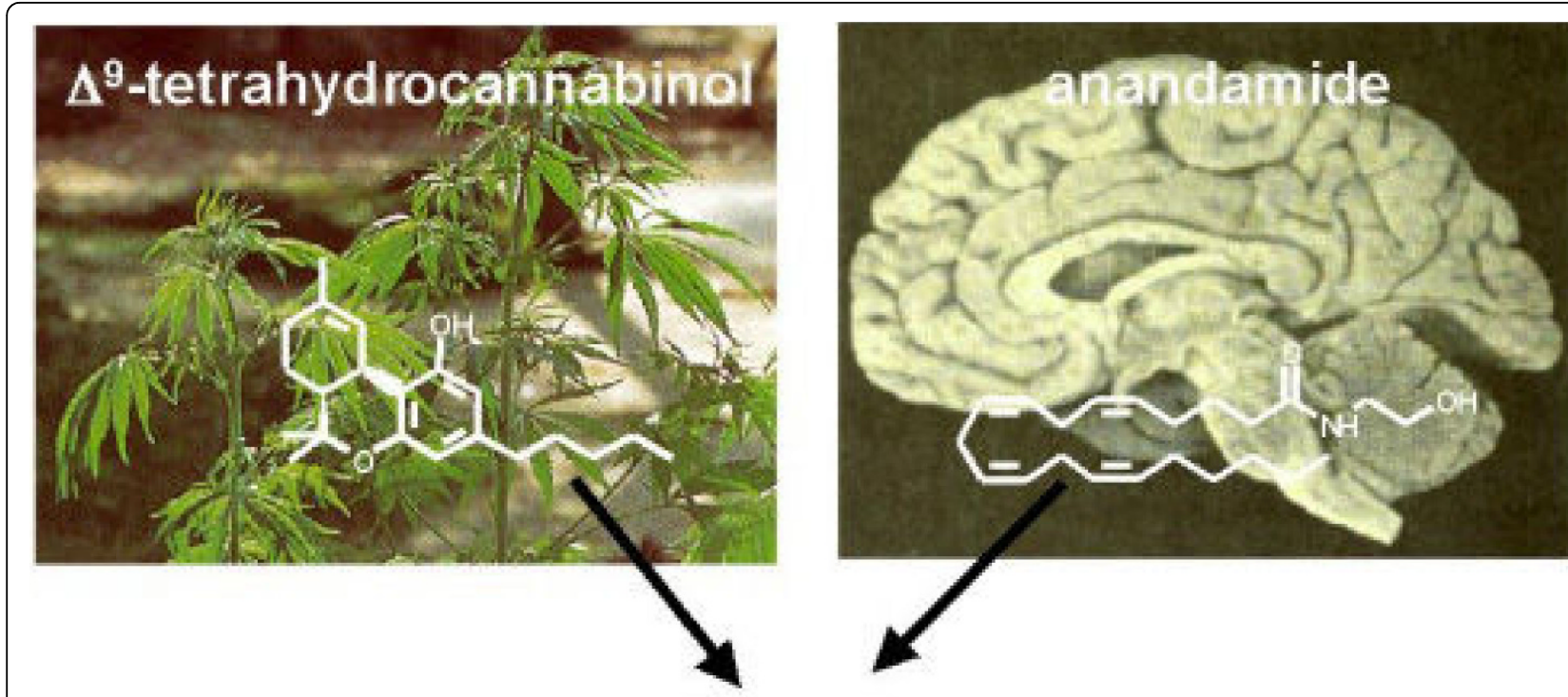

\section{cannabinoid receptor}

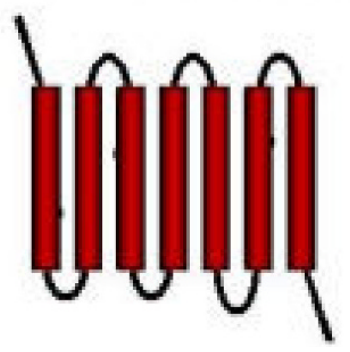

Figure 1 Both $\Delta^{9}$-tetrahydrocannabinol, the psychoactive component of Cannabis sativa, and anandamide, an endogenous neurotransmitter in the human brain, bind to the same cannabinoid receptor. (Photos/Diagrams from the Max Planck Institute of Psychiatry [42]).

[27]. Another investigation confirmed this notion showing that different routes of $\Delta^{9}$-THC administration (oral, smoke inhalation or suppository) induced an effect on food selection [28]. Moreover, this selective action on food choice was confirmed in a number of animal studies, in which a potential role of cannabinoids in modulating the interaction of different pathways involved in the brain 'reward' system was hypothesized $[29,30]$. Thus, endocannabinoid signaling is involved orexigenically in both the homeostatic and the hedonistic control of food intake [31].

\section{Endocannabinoid actions in the periphery Adipocytes}

A functional $\mathrm{CB}_{1}$ receptor has already been identified in the fat tissue of rodents [25]. The $\mathrm{CB}_{1}$ receptor is expressed both in epididymal fat pads extracted from mice and in primary adipocyte cell cultures and seems to be involved in the regulation of lipogenesis. Moreover, the receptor is expressed in fat tissue obtained from $\mathrm{CB}_{1+/+}$, but not $\mathrm{CB}_{1-/-}$ knockout, mice. $\mathrm{CB}_{1}$ agonists dose-dependently increase lipoprotein lipase activity in adipocyte cell cultures, and this effect can be blocked by the preincubation with the $\mathrm{CB}_{1}$ selective antagonist rimonabant, thus confirming a specific cannabinoid mechanism of action [25].

Interestingly, the blockade of $\mathrm{CB}_{1}$ receptors, either in vivo or in adipocyte cell cultures, results in a significant increase of adiponectin production [32]. Adiponectin is secreted exclusively by adipose tissue, with plasma levels negatively correlated with obesity [33]. Moreover, adiponectin is the only adipocytokine with anti-inflammatory effects and with a protective role against atherosclerosis, in addition to its insulin sensitizer effect [34]. The modulation of the endocannabinoid system using a chronic oral treatment with rimonabant simultaneously reduces body weight and stimulates adiponectin mRNA expression in adipose tissue of obese Zucker rats [32]. In parallel, the hyperinsulinemia associated with this experimental model was reduced by rimonabant 


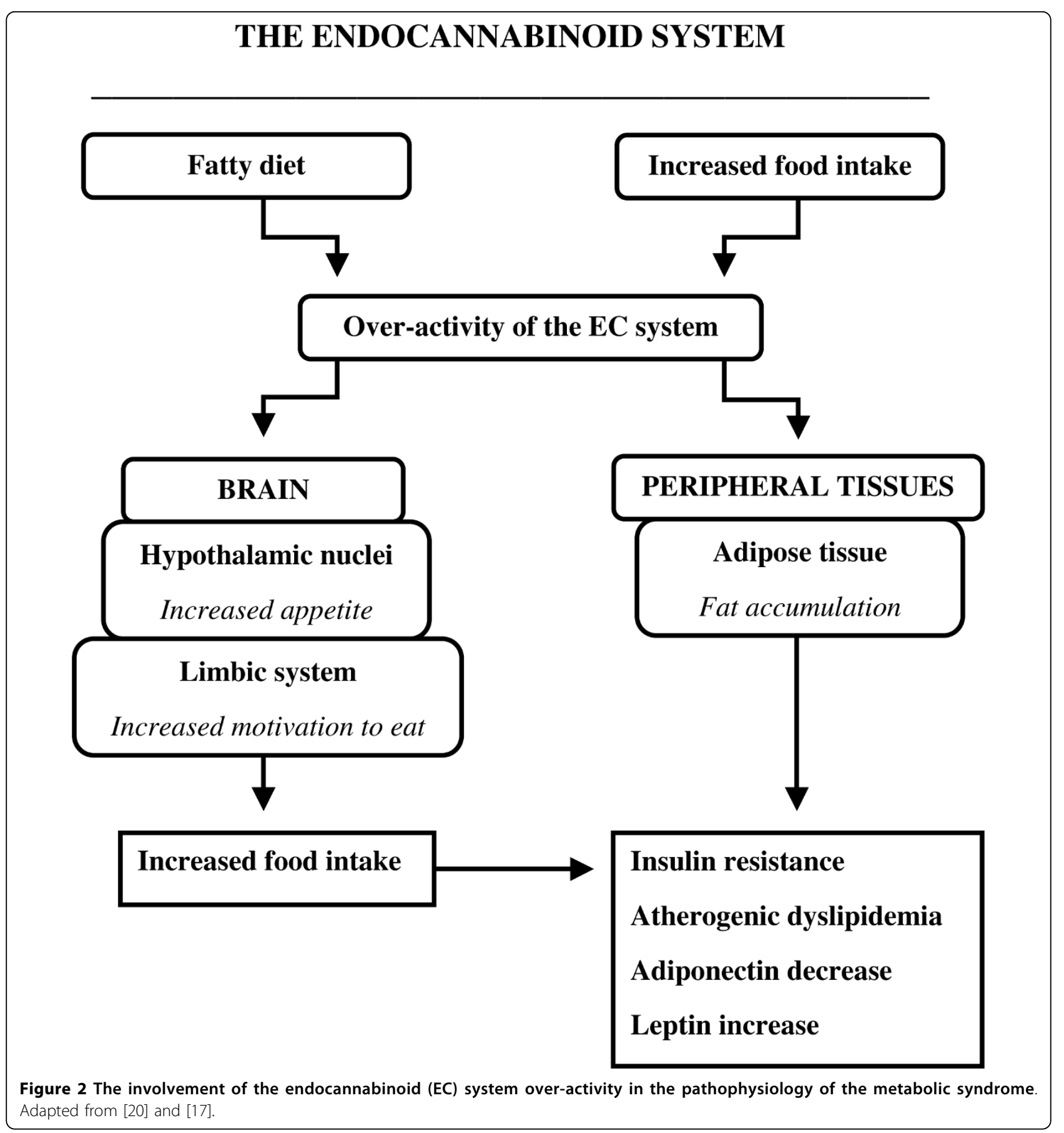

treatment [32]. Moreover, adiponectin expression is upregulated by the blockade of $\mathrm{CB}_{1}$ receptors only in $\mathrm{CB}_{1}$ ${ }_{+/+}$, but not $\mathrm{CB}_{1-/-}$ knockout, mice [32].

\section{Skeletal muscle}

It has already been shown that the modulation of the endocannabinoid system regulates glucose uptake through the phosphatidylinositol-3-kinase pathway in skeletal muscle cells [35]. Accordingly, the blockade of peripheral $C_{1}$ receptors could contribute to the improvement of glycemia observed in clinical trials with rimonabant [36]. In this context, Liu et al. clearly demonstrated that a sub-acute treatment with rimonabant increases soleus muscle glucose uptake in leptindeficient obese mice [37].

Liver

The presence of $\mathrm{CB}_{1}$ receptors in the mouse liver has been confirmed using multiple methodological approaches [38], indicating that the hepatocyte could be 
Table 1 Central and peripheral sites of action of $\mathrm{CB}_{1}$ receptor antagonists and outcomes of the blockade of the endocannabinoid (EC) system.

\begin{tabular}{ccc}
\hline SITE OF ACTION & MECHANISMS OF ACTION & BLOCKADE OF EC SYSTEM EFFECTS \\
\hline Hypothalamic nuclei & $\downarrow$ food intake & $\begin{array}{c}\text { body weight } \\
\text { waist circumference }\end{array}$ \\
\hline Adipose tissue & $\begin{array}{c}\uparrow \text { adiponectin } \\
\downarrow \text { lipogenesis }\end{array}$ & $\begin{array}{c}\text { dyslipidemia } \\
\text { insulin resistance }\end{array}$ \\
\hline Skeletal muscle & $\uparrow$ glucose uptake & insulin resistance \\
\hline Liver & $\downarrow$ lipogenesis & $\begin{array}{c}\text { dyslipidemia } \\
\text { insulin resistance }\end{array}$ \\
\hline Gastrointestinal tract & $\uparrow$ satiety signals & body weight \\
& & waist circumference \\
\hline
\end{tabular}

a peripheral molecular target of the endocannabinoid system. In fact, the activation of the $\mathrm{CB}_{1}$ receptor increases the expression of lipogenic genes in the liver, which is the main source of de novo fatty acid synthesis in the body [38].

Synthetic agonists of the $C_{1}$ receptor induce the expression of several key lipogenic enzymes in liver, an effect that is prevented by a pretreatment with $\mathrm{CB}_{1}$ receptor antagonists [38]. Moreover, the basal rates of de novo fatty acid synthesis are markedly increased in $\mathrm{CB}_{1+/+}$ mice submitted to a high fat diet (HFD), compared with those of lean controls, but not in the $\mathrm{CB}_{1-/-}$ knockout mice [38]. The pretreatment of $\mathrm{CB}_{1+/+}$ mice on HFD with a $C_{1}$ receptor antagonist reduces the rate of fatty acid synthesis [38]. In mice on HFD, the hepatic levels of the endocannabinoid anandamide were also greatly elevated. Finally, a marked deposition of lipid droplets was evident in wild-type, but not $\mathrm{CB}_{1-/ \text { - mice }}$ on HFD [38], suggesting the involvement of cannabinoid activation in liver steatosis.

\section{Conclusions}

The endocannabinoid system is present and has important physiological functions not only in the central nervous system but also in peripheral tissues. The activation of central $\mathrm{CB}_{1}$ receptors, particularly in hypothalamic nuclei and in the limbic system, is involved in the regulation of feeding behavior, and especially in the control of the intake of palatable food. It is important to mention that the activation of the endocannabinoid system, in addition to increasing appetite (total food intake), also influences the palatability and the preferential choice of tasty and sweet foods [5] (Figure 2). Thus, endocannabinoid antagonists could be utilized for the treatment of the type of obesity associated with specific eating disorders such as 'sweet and snackeating' and compulsive eating episodes.

In the periphery, cannabinoid receptors are present in adipocytes, skeletal muscle, gastrointestinal tract and liver, modulating energy metabolism (Table 1).
In conclusion, the endocannabinoid system seems to play a key role in the development and maintenance of obesity (see previous reviews $[5,39,40]$ ). In obese patients, excessive food intake, especially of sweet and palatable food, could lead to the hyperactivity of the endocannabinoid system, resulting in several metabolic alterations typical of the metabolic syndrome (Figure 1). Thus, the pharmacological modulation of the endocannabinoid system turns out to be a unique target in the treatment of those that are overweight or obese [41].

\section{Abbreviations}

$\Delta^{9}$-THC: $\Delta^{9}$-tetrahydrocannabinol; $\mathrm{CB}_{1}$ : type 1 cannabinoid receptor; $\mathrm{CB}_{2}$ : type 2 cannabinoid receptor; VMH: ventromedial hypothalamus; HFD: high-fat diet.

\section{Authors' contributions}

ET conceived and wrote the manuscript. All authors read and approved the final manuscript.

\section{Competing interests}

The author declares that they have no competing interests.

Received: 26 March 2009

Accepted: 21 January 2010 Published: 21 January 2010

\section{References}

1. Li HL, Lin H: An archaeological and historical account of cannabis in China. Econ Bot 1974, 28(4):437-447

2. Di Marzo V, Petrocellis LD: Plant, synthetic, and endogenous cannabinoids in medicine. Annu Rev Med 2006, 57:553-74.

3. Kogan NM, Mechoulam R: Cannabinoids in health and disease. Dialogues Clin Neurosci 2007, 9(4):413-30.

4. Abel EL: Cannabis: effects on hunger and thirst. Behav Biol 1975, 15(3):255-81.

5. Cota $D$, et al: Endogenous cannabinoid system as a modulator of food intake. Int J Obes Relat Metab Disord 2003, 27(3):289-301.

6. De Petrocellis L, Cascio MG, Di Marzo V: The endocannabinoid system: a general view and latest additions. Br J Pharmacol 2004, 141(5):765-74.

7. Rodriguez de Fonseca $F$, et al: The endocannabinoid system: physiology and pharmacology. Alcohol Alcohol 2005, 40(1):2-14

8. Gaoni Y, Mechoulam R: Isolation, structure and partial synthesis of an active constituent of hashish. J Am Chem Soc 1964, 86:1646.

9. Matsuda LA, et al: Structure of a cannabinoid receptor and functional expression of the cloned cDNA. Nature 1990, 346(6284):561-4.

10. Munro S, Thomas KL, Abu-Shaar M: Molecular characterization of a peripheral receptor for cannabinoids. Nature 1993, 365(6441):61-5. 
11. Howlett AC, et al: International Union of Pharmacology. XXVII Classification of cannabinoid receptors. Pharmacol Rev 2002, 54(2):161-202.

12. Schlicker $\mathrm{E}$, Kathmann M: Modulation of transmitter release via presynaptic cannabinoid receptors. Trends Pharmacol Sci 2001, 22(11):565-72.

13. Devane $W A$, et al: Isolation and structure of a brain constituent that binds to the cannabinoid receptor. Science 1992, 258(5090):1946-9.

14. Felder CC, et al: Isolation and measurement of the endogenous cannabinoid receptor agonist, anandamide, in brain and peripheral tissues of human and rat. FEBS Lett 1996, 393(2-3):231-5,

15. Hanus $L$, et al: Two new unsaturated fatty acid ethanolamides in brain that bind to the cannabinoid receptor. J Med Chem 1993, 36(20):3032-4.

16. Berry EM, Mechoulam R: Tetrahydrocannabinol and endocannabinoids in feeding and appetite. Pharmacol Ther 2002, 95(2):185-90.

17. Di Marzo V, Matias I: Endocannabinoid control of food intake and energy balance. Nat Neurosci 2005, 8(5):585-9.

18. Kirkham TC: Endocannabinoids in the regulation of appetite and body weight. Behav Pharmacol 2005, 16(5-6):297-313.

19. Sharkey KA, Pittman QJ: Central and peripheral signaling mechanisms involved in endocannabinoid regulation of feeding: a perspective on the munchies. Sci STKE 2005, 2005(277):pe15.

20. Pagotto $U$, et al: The emerging role of the endocannabinoid system in endocrine regulation and energy balance. Endocr Rev 2006, 27(1):73-100.

21. Pacher $P$, Batkai $S$, Kunos $G$ : The endocannabinoid system as an emerging target of pharmacotherapy. Pharmacol Rev 2006, 58(3):389-462.

22. Jamshidi N, Taylor DA: Anandamide administration into the ventromedial hypothalamus stimulates appetite in rats. Br J Pharmacol 2001, 134(6):1151-4.

23. Kirkham TC, et al: Endocannabinoid levels in rat limbic forebrain and hypothalamus in relation to fasting, feeding and satiation: stimulation of eating by 2-arachidonoyl glycerol. Br J Pharmacol 2002, 136(4):550-7.

24. Ravinet Trillou C, et al: CB1 cannabinoid receptor knockout in mice leads to leanness, resistance to diet-induced obesity and enhanced leptin sensitivity. Int J Obes Relat Metab Disord 2004, 28(4):640-8.

25. Cota $D$, et al: The endogenous cannabinoid system affects energy balance via central orexigenic drive and peripheral lipogenesis. J Clin Invest 2003, 112(3):423-31.

26. Ravinet Trillou C, et al: Anti-obesity effect of SR14 a CB1 receptor antagonist, in diet-induced obese mice. Am J Physiol Regul Integr Comp Physiol 1716, 284(2):R345-53.

27. Foltin RW, Fischman MW, Byrne MF: Effects of smoked marijuana on food intake and body weight of humans living in a residential laboratory. Appetite 1988, 11(1):1-14.

28. Mattes RD, et al: Cannabinoids and appetite stimulation. Pharmacol Biochem Behav 1994, 49(1):187-95.

29. Williams CM, Kirkham TC: Anandamide induces overeating: mediation by central cannabinoid (CB1) receptors. Psychopharmacology (Berl) 1999, 143(3):315-7.

30. Koch JE: Delta(9)-THC stimulates food intake in Lewis rats: effects on chow, high-fat and sweet high-fat diets. Pharmacol Biochem Behav 2001, 68(3):539-43.

31. Vemuri VK, Janero DR, Makriyannis A: Pharmacotherapeutic targeting of the endocannabinoid signaling system: drugs for obesity and the metabolic syndrome. Physiol Behav 2008, 93(4-5):671-86.

32. Bensaid $M$, et al: The cannabinoid CB1 receptor antagonist SR141716 increases Acrp30 mRNA expression in adipose tissue of obese fa/fa rats and in cultured adipocyte cells. Mol Pharmacol 2003, 63(4):908-14

33. Arita $Y$, et al: Paradoxical decrease of an adipose-specific protein, adiponectin, in obesity. Biochem Biophys Res Commun 1999, 257(1):79-83.

34. Goldstein BJ, Scalia R: Adiponectin: A novel adipokine linking adipocytes and vascular function. J Clin Endocrinol Metab 2004, 89(6):2563-8.

35. Esposito I, et al: The cannabinoid CB1 receptor antagonist Rimonabant stimulates 2-deoxyglucose uptake in skeletal muscle cells by regulating phosphatidylinositol-3-kinase activity. Mol Pharmacol 2008.

36. Scheen AJ: CB1 receptor blockade and its impact on cardiometabolic risk factors: overview of the RIO programme with rimonabant. J Neuroendocrinol 2008, 20(Suppl 1):139-46.

37. Liu YL, et al: Effects of the cannabinoid CB1 receptor antagonist SR141716 on oxygen consumption and soleus muscle glucose uptake in Lep(ob)/Lep(ob) mice. Int J Obes (Lond) 2005, 29(2):183-7.
38. Osei-Hyiaman D, et al: Endocannabinoid activation at hepatic CB1 receptors stimulates fatty acid synthesis and contributes to diet-induced obesity. J Clin Invest 2005, 115(5):1298-305.

39. Kirkham TC, Williams CM: Endogenous cannabinoids and appetite. Nutr Res Rev 2001, 14(1):65-86.

40. Cota $D$, et al: Antagonizing the cannabinoid receptor type 1: a dual way to fight obesity. J Endocrinol Invest 2003, 26(10):1041-4.

41. Murro AL: The endocanabinnoid system and diabetes - critical analyses of studies conducted with rimonabant. Diabetol Metab Syndr 2009, 1(1):18

42. Max Planck Institute of Psychiatry. News Release - Max Planck Society 2002, 17.

doi:10.1186/1758-5996-2-5

Cite this article as: Tibiriça: The multiple functions of the

endocannabinoid system: a focus on the regulation of food intake.

Diabetology \& Metabolic Syndrome 2010 2:5.

\section{Submit your next manuscript to BioMed Central and take full advantage of:}

- Convenient online submission

- Thorough peer review

- No space constraints or color figure charges

- Immediate publication on acceptance

- Inclusion in PubMed, CAS, Scopus and Google Scholar

- Research which is freely available for redistribution 